\title{
Storytelling in Business-to-Business Advertising: An Abstract
}

\author{
Nwamaka A. Anaza, Elyria Kemp, and Leila Aberdeen Borders
}

\begin{abstract}
Past academic research addressing storytelling has mainly been approached from the business-to-consumer (B2C) context. These studies have credited stories as a fundamental source for emotional buying behavior in consumers. Although storytelling has the ability to evoke greater emotions in consumers, marketing research has not examined its application in the business-to-business (B2B) context, particularly within the advertising realm. Drawing on the B2C literature, this study offers an exploratory examination of the benefits of storytelling in B2B advertising. The authors reveal that stories told to organizational buyers foster a deeper, emotional connection to the selling firm. Results directly indicate that there is indeed power in telling stories to members of the buying center because it influences their purchase behavior and decision-making process. We also demonstrate that there is significance in telling stories to organizational buyers who have been historically thought of as purely rational beings. In fact, our findings debunk the notion that organizational buyers respond to marketing communications on the basis of economic value alone. At the heart of this research, we establish that storytelling can be fruitful in B2B advertising.
\end{abstract}

\author{
N. A. Anaza $(\bowtie)$ \\ Southern Illinois University Carbondale, Carbondale, IL, USA \\ e-mail: nanaza@siu.edu \\ E. Kemp \\ University of New Orleans, New Orleans, LA, USA \\ e-mail: ekemp@uno.edu \\ L. A. Borders \\ Kennesaw State University, Kennesaw, GA, USA \\ e-mail: aborder4@kennesaw.edu
}

